\title{
Comunicação
}

[Communication]

\section{Proporção volumétrica dos constituintes do corpo lúteo de Nelore}

\author{
M.M. Neves, A.P. Marques $J r$ * \\ Escola de Veterinária da UFMG \\ Caixa postal 567 \\ 30123-970 - Belo Horizonte, MG
}

[Volumetric proportions of the corpus luteum constituints of Nelore]

O corpo lúteo, uma glândula endócrina transitória, apresenta períodos regulares de formação, função e luteólise marcados por intensa remodelação tecidual, caracterizada pela proliferação, migração, diferenciação e morte celular. O corpo lúteo possui populações heterogêneas de células com características morfofuncionais e bioquímicas distintas, classificadas como células esteroidogênicas e não-esteroidogênicas (Schams e Berisha, 2004).

As células esteroidogênicas do corpo lúteo bovino são denominadas células luteínicas maiores e células luteínicas menores. As células luteínicas maiores apresentam diâmetro entre 23 e $50 \mu \mathrm{m}$, núcleo esférico e grânulos citoplasmáticos que contém ocitocina. As menores, diâmetro entre 12 e $22 \mu \mathrm{m}$, núcleo com formato irregular e gotículas lipídicas no citoplasma. As células luteínicas maiores produzem $80 \%$ da progesterona basal, enquanto as menores apenas $20 \%$ e ocupam, respectivamente, 40 e $20 \%$ do volume luteal e 3 e $26 \%$ do total de células do corpo lúteo bovino (Diaz et al., 2002).

Células não-esteroidogênicas compreendem diferentes tipos celulares, como as células endoteliais, os pericitos e os fibroblastos. As células endoteliais correspondem a $14 \%$ do volume luteal e a $53 \%$ das células do corpo lúteo bovino. Os pericitos são células alongadas, localizadas em espaços da lâmina basal que rodeiam o endotélio capilar, com capacidade fagocitária, de secreção e contração, além de originarem diferentes tipos celulares. Os fibroblastos representam $6 \%$ do volume luteal e $10 \%$ do total celular (Fields e Fields, 1996; Gaytán et al., 1997; Geneser, 2003).

Não foram encontrados trabalhos sobre avaliação morfométrica do corpo lúteo de animais da raça Nelore. O objetivo deste trabalho é avaliar a proporção volumétrica dos constituintes celulares do corpo lúteo em animais Nelore, considerando os estádios fisiológicos reprodutivos nãogestante e gestante.

Foram utilizados ovários de 17 vacas e novilhas da raça Nelore abatidas em frigorífico. Após o abate, os órgãos genitais foram retirados, separando-se os ovários com corpo lúteo que apresentava características de funcionalidade. Os espécimens foram classificados em dois grupos: o grupo I (GI) com sete animais não-gestantes e o grupo II (GII), com 10 animais gestantes, cujo tempo de gestação foi determinado mensurandose e aplicando-se o valor do comprimento ápicocaudal do feto à fórmula $\mathrm{X}=2,5(\mathrm{Y}+21)$, descrita por Richardson (1980) citado por Arthur et al. (1989), em que X é a variável tempo de gestação em dias, e Y representa o comprimento ápicocaudal do feto em centímetros. Nesse grupo, foram encontradas gestações de até 90 dias e gestações acima de 150 dias.

Recebido em 25 de novembro de 2005

Aceito em 4 de setembro de 2006

* Autor para correspondência (corresponding author)

E-mail: ampinho@ufmg.br 
O corpo lúteo foi dissecado do ovário e reduzido a cortes menores que $3 \mathrm{~mm}$, sendo utilizado apenas um corte para fixação em solução de Bouin por 24 horas. O corte foi processado segundo a técnica rotineira de inclusão em parafina, cortado à espessura de $5 \mu \mathrm{m}$ em micrótomo e corado pela técnica de hematoxilina e eosina. A proporção volumétrica dos constituintes do corpo lúteo, como citoplasma e núcleo das células luteínicas, tecido conjuntivo e fibroblastos, células endoteliais e pericito foi obtida utilizando-se ocular integradora Zeiss KPL 10X com retículo de cinco linhas horizontais e 25 pontos eqüidistantes, totalizando 875 pontos/corpo lúteo/animal (Neves e Marques Jr., 2002). O diâmetro nuclear médio das células luteínicas maiores e menores foi obtido mensurando-se 20 núcleos de cada tipo celular por animal com lente micrométrica Olympus acoplada à objetiva de 100X. Aplicou-se às médias finais o fator de correção obtido pela escala de uma lâmina micrométrica.

O delineamento experimental foi inteiramente ao acaso, sendo os resultados submetidos à análise de variância e as diferenças entre médias comparadas pelo teste $t$ de Student $(\mathrm{P}<0,05)$.

$\mathrm{Na}$ proporção volumétrica dos constituintes do corpo lúteo (Tab. 1), os animais do GI apresentaram médias maiores do que os do GII para o citoplasma e núcleo das células luteínicas, sugerindo que na fase de maior atividade do corpo lúteo bovino há predomínio das células esteroidogênicas nos animais não-gestantes, semelhante ao relatado por Parry et al. (1980). Nas células endoteliais e pericito não houve diferença entre os grupos $(\mathrm{P}>0,05)$. $\mathrm{O}$ poder do teste para essa característica foi baixo, o que sugere influência individual no resultado e, portanto, sua interpretação cautelosa. A média para tecido conjuntivo e fibroblastos no GII foi maior que no GI. Esse resultado reflete o observado à avaliação histológica, de que as células luteínicas do corpo lúteo de animais com mais de 150 dias de gestação apresentaram espaço intercelular maior que o do GI.

Tabela 1. Médias e desvios-padrão da proporção volumétrica do citoplasma das células luteínicas, núcleo das células luteínicas, tecido conjuntivo e fibroblastos e células endoteliais e pericitos do corpo lúteo de animais Nelore não-gestantes (GI) e gestantes (GII) abatidos em frigorífico da Região Metropolitana de Belo Horizonte - MG

\begin{tabular}{lcc}
\hline Proporção volumétrica & GI & GII \\
\hline Citoplasma das células luteínicas & $46,7 \pm 5.36 \mathrm{a}$ & $41,0 \pm 2,42 \mathrm{~b}$ \\
Núcleo das células luteínicas & $6,13 \pm 1,27 \mathrm{a}$ & $4,25 \pm 1,03 \mathrm{~b}$ \\
Células endoteliais e pericito & $8,37 \pm 3,75 \mathrm{a}$ & $6,69 \pm 2,56 \mathrm{a}$ \\
Tecido conjuntivo e fibroblastos & $38,8 \pm 3,94 \mathrm{~b}$ & $48,1 \pm 4,23 \mathrm{a}$ \\
\hline
\end{tabular}

Médias com letras distintas na linha diferem entre si $(\mathrm{P}<0,05)$ pelo teste $t$ de Student.

As médias do diâmetro nuclear das células luteínicas maiores e menores não diferiram entre grupos $(\mathrm{P}>0,05)$, sendo de $8,6 \pm 0,59$ para as células maiores de GI e GII e de 5,81 $\pm 0,41$ e $5,87 \pm 0,41$ para as células menores dos grupos GI e GII, respectivamente. Este resultado sugere que o diâmetro nuclear das células luteínicas maiores e menores não varia com o estádio fisiológico reprodutivo, semelhante ao relatado por Sawyer (1995), que o tamanho das células esteroidogênicas permanece relativamente constante dos 14 aos 142 dias de gestação.

Palavras-chave: bovino, Nelore, corpo lúteo, morfometria

\section{ABSTRACT}

Volumetric proportions and nuclear diameter of the small and large luteinic cells of the corpus luteum (CL) were evaluated in ovaries of 17 Nelore cows and heifers, collected in slaughterhouse and classified into two groups: group I (GI, $n=7)$, non-pregnant animals, and group II (GII, $n=10)$, pregnant animals. The CL was reduced to small cuts (less than $3 \mathrm{~mm}$ ), which were fixed in Bouin solution and processed for 
morphometric analysis. The volumetric proportion analysis showed higher mean in the GI animals for the nuclei and cytoplasm of luteinic cells, while the mean of connective tissue and fibroblasts was higher in the GII animals, while the mean of the capillary endothelial cells and pericytes did not differ between the groups. The average nuclear diameter of the large and small luteinic cells did not differ between the groups.

Keywords: bovine, Nelore, corpus luteum, morphometry

\section{REFERÊNCIAS BIBLIOGRÁFICAS}

ARTHUR, G.H.; NOAKES, D.E.; PEARSON, $\mathrm{H}$. Veterinary reproduction and obstetrics. 6.ed. Londres: Baillière Tindall, 1989. cap. 2: The development of the cocenptus. p.49-59.

DÍAZ, F.J.; ANDERSON, L.E.; WU, Y.L. et al. Regulation of progesterone and prostaglandin $\mathrm{F}_{2 \alpha}$ production in the CL. Mol. Cell. Endocrinol., v.191, p.65-80, 2002.

FIELDS, M.J.; FIELDS, P.A. Morphological characteristics of the bovine corpus luteum during the estrous cycle and pregnancy. Theriogenology, v.45, p.1295-1325, 1996.

GAYTÁN, F.; BELLIDO, C.; MORALES, C. et al. Evidence for steroidogenic luteal cell hypertrophy and hyperplasia during pregnancy in the rat. J. Endocrionol., v.154, p.211-217, 1997.
GENESER, F. Histologia. 3.ed. Rio de Janeiro: Guanabara Koogan, 2003. 616p.

NEVES, M.M.; MAQUES Jr., A.P. Tamanho amostral para estudo da proporção volumétrica dos constituintes do corpo lúteo bovino. Arch. Vet. Sci., v.7, p.81-85, 2002.

PARRY, D.M.; WILCOX, D.L.; THORBURN, G.D. Ultrastructural and cytochemical study pf the bovine corpus luteum. J. Reprod. Fertil., v.60, p.349-357, 1980.

SAWYER, H.R. Structural and functional properties of the corpus luteum of pregnancy. $J$. Reprod. Fertil, v.45, suppl., p.97-110, 1995.

SCHAMS, D.; BERISHA, B. Regulation of corpus luteum function in cattle - an overview. Reprod. Dom. Anim., v.39, p.241-251, 2004. 